\title{
Expressive prosody in children with autism spectrum conditions
}

\author{
Susan Peppé ${ }^{\mathrm{a}, *}$, Joanne Cleland $^{\mathrm{a}}$, Fiona Gibbon ${ }^{\mathrm{b}}$, Anne O’Hare ${ }^{\mathrm{c}}$, \\ Pastora Martínez Castilla ${ }^{\mathrm{d}}$ \\ ${ }^{a}$ Department of Speech and Hearing Sciences, Queen Margaret University, Edinburgh EH21 6UU, UK \\ ${ }^{\mathrm{b}}$ Department of Speech and Hearing Sciences, Brookfield Health Sciences Complex University College Cork, College Road, Cork, Ireland \\ ${ }^{\mathrm{c}}$ Department of Reproductive \& Developmental Medicine, University of Edinburgh, 10 Chalmers Crescent, Edinburgh EH9 1TS, UK \\ ${ }^{\mathrm{d}}$ Universidad a Distancia de Madrid, Spain
}

\section{A R T I C L E I N F O}

Article history:

Received 31 March 2010

Received in revised form 19 July 2010

Accepted 20 July 2010

\section{Keywords:}

Autism

Prosody

Intonation

Language

\begin{abstract}
A B S T R A C T
The expressive prosodic abilities of two groups of school-age children with autism spectrum conditions (ASC), Asperger's syndrome (AS) and high-functioning autism (HFA), were compared with those of typically-developing controls. The HFA group showed impairment relative to age-matched controls on all the prosody tasks assessed (affect, sentence-type, contrastive stress, phrasing and imitation) while the AS showed impairment only on phrasing and imitation. Compared with lexically-matched controls, impairment on several tasks (affect, contrastive stress and imitation) was found in the HFA group but little in the AS group (phrasing and imitation). Comparisons between the ASC groups showed considerable differences on prosody skills. Impairment in prosodic skills may therefore be a reliable indicator of autism spectrum subgroups, at least as far as communicative functioning is concerned. There were also significant differences between ASC groups and lexically-matched typically-developing children on expressive language skills, but the incomplete correlation of the prosody results with scores on language tasks suggests that the prosodic differences between the two groups may not all be attributable to the level of language skills. Suggested further research is to investigate the relationship of prosody and language skills in this population more closely, and to develop a prosody test as part of the diagnostic criteria of ASC.
\end{abstract}

(c) 2010 Elsevier Ltd. All rights reserved.

\footnotetext{
* Corresponding author. Tel.: +4401848 200770.

E-mail address: sue.peppe@gmail.com (S. Peppé).
} 


\section{Introduction}

Prosody, or manner of speaking, was noted as atypical in the original identification of autism by Leo Kanner (Kanner, 1943) and this has since been affirmed by many authors, e.g. Ehlers and Gillberg (1993), Klin and Volkmar (1995), Wing $(1981,1991)$. The prosody of verbal people with autism spectrum conditions (ASC) has however not received a great deal of attention in research. There are several possible reasons why this should be, such as the variability of atypical prosody and the difficulty of assessing its communicative and social effects (Peppé, 2009). There are at least three reasons for investigating it: to find out how communication and social interaction in people who have the condition may be affected by deficits in prosodic skills; to establish the basis for possible techniques for intervention and improvement in aspects of communication in ASC; and to shed light on typical language development. This paper is concerned mainly with the first reason.

Another aspect addressed by this paper is the distinction between Asperger's syndrome (AS) and high-functioning autism (HFA), the principal difference being the degree and type of language impairment: characteristics of the two conditions are described in more detail below (1.2). This has been a topic of interest to other researchers (e.g. Macintosh \& Dissayanake, 2004; Szatmari et al., 2009). The classification of ASC subtypes can be useful with regard to predictive validity of diagnosis, treatment response, and for matching interventions to the needs of individual children.

\subsection{Atypical prosody}

The functions of prosody include verbal punctuation or phrasing; the expression of feelings and affect by intonation and tone of voice; indicating utterance-type, i.e., whether a conversational utterance is a question, a statement, or an invitation to continue speaking; and signalling the focal point of an utterance (Roach, 2000). These functions are conveyed by the forms of prosody which depend on variations of loudness, pitch and articulation rate. Additionally, individual speakers have idiosyncratic variations; prosodic styles vary in their appropriateness; and many languages have regional prosodic varieties. All this makes it hard to determine prosody as typical or atypical (Peppé, 2009), the more so as prosodic phenomena are not well-defined and seldom explicitly discussed; but this has not prevented a sense that prosody can be wrong or unusual, as in the above-mentioned early characterisations of ASC and in lay perceptions of autistic speech.

The perception of expressive prosody as atypical or disordered has at least two implications. One is that atypical expressive prosody produces an impression that the speaker is 'different', with the inevitable consequences for social integration. The other is the implication for communication: that disordered prosodic ability, receptive or expressive, may lead to misunderstandings. People with ASC display many variations of atypical prosody, and it is not known to what degree any form of it affects communication and social interaction, but for clinicians, carers and educators it would be helpful to be able to characterise the primary problems. The implications for functional communication will be considered in this paper and an experiment in the perception of atypical expressive prosody by people not professionally concerned with communication disorders will be the subject of another paper (Peppé, Cleland, Gibbon, O'Hare, Martinez Castilla, \& Lickley, in preparation).

\subsection{Previous research}

As part of a previous project we conducted a review of the available literature on prosody in ASC (McCann \& Peppé, 2003), which showed it to be fairly sparse (16 studies in 22 years). Some of the studies concluded that there was a tendency in ASC to misplace stress in utterances (Baltaxe \& Guthrie, 1987; Shriberg et al., 2001). Many studies showed inconclusive results and no consistent picture of prosody as a whole in high-functioning ASC emerged: this was however not surprising, as the definition and scope of what constitutes both autism and prosody varied from study to study. Many of the studies suffered from a paucity of participants. It also emerged that the descriptions of atypical autistic prosody varied widely: it could be exaggerated, monotonous, robotic, stilted, wooden, and sometimes sound as 
though the speaker had a foreign accent. Prosody to which the terms 'exaggerated' and 'monotonous' can both be applied suggests either a confusion of terminology or different manifestations.

Since then there have been further studies, for example a major study by Paul, Augustyn, Klin, and Volkmar (2005), examining various aspects of receptive and expressive prosody in a systematic way in a cohort of participants, involving 13 typically-developing controls and 27 participants with ASC. Their findings support those of earlier studies; e.g. the group with ASC had difficulty with placing stress correctly in pragmatic and affective contexts, and in placing stress in accordance with canonical lexical stress patterns.

Our own study of prosody in children with high-functioning autism (HFA) is reported in Peppé, McCann, Gibbon, O'Hare, and Rutherford (2007). On several of the prosody tasks there were marked differences between the experimental group and controls, with the children in the HFA group performing significantly less well on several aspects of both receptive and expressive prosody. There was a tendency to misplace stress in the HFA group, in line with previous findings. The HFA group also had difficulty with the understanding and expression of utterances differentiated by affect: this was predictable, given the low ability of people with ASC to infer the feelings of others and to express their own feelings (as indicated in, for example, Ben Shalom et al., 2006; Capps, Yirmiya, \& Sigman, 1992). The HFA group also performed significantly worse on imitation tasks, where they had to listen to a short phrase and repeat it with matching prosody. The HFA and control groups were matched on a receptive vocabulary measure, and it therefore appears that in this type of ASC prosodic ability, while strongly correlated with language ability (McCann, Peppé, Gibbon, O’Hare, \& Rutherford, 2007), was to some extent impaired independently of language.

We were however interested in how the prosody skills of a group of children with AS, as differentiated by language delay history, would compare with those of the HFA group, i.e., whether prosodic ability would keep pace with the better language ability of children with AS. It is controversial as to whether Asperger's syndrome constitutes a particular type of high-functioning autism or is a separate category (Fitzgerald \& Corvin, 2001; Harrison, O'Hare, Campbell, Adamson, \& McNeillage, 2006). Matson (2007) and Macintosh and Dissayanake (2004) conclude that there are no etiologic differences between AS and HFA, but recent diagnostic criteria hold that they are distinguished by a history of clinically significant pre-school language delay, present in HFA but not in AS (as in, e.g. Cederlund, Hagberg, Billstedt, Gillberg, \& Gillberg, 2008; Howlin, 2003). A recent paper (Szatmari et al., 2009) used the more precise clinical feature of absence of structural language impairment (StrLI)' to distinguish AS from HFA, or thought of HFA as "really AS 'co-morbid with StrLl" (p. 1465, their italics), and found similar developmental trajectories: both groups improved at roughly the same rate and in both the rate of improvement slowed down in late adolescence. They noted however that ways of defining and measuring StrLI might be refined in future; given the disjunction in prosodic ability in our HFA study when participants were matched on receptive vocabulary, the role of prosody in both types of ASC is interesting from this point of view.

\subsection{Aims}

The present paper takes into account data from both our HFA study and a later one we conducted with children with AS, similar to the HFA study but with extended scope. Both studies set out to discover the functional prosodic ability and prosodic imitation skills of children with ASC. In this paper we compare expressive prosodic ability in the two ASC groups, comparing them with both age-matched and lexically-matched controls, looking at the ability both to imitate prosody and to use it in a functional way for communication. We also look at the differences between the two groups in the relationship between prosodic and linguistic skills as measured by their performance on an expressive language task. By this means we aim to establish how closely differences in prosodic expressive ability between the two ASC groups are related to their expressive language skills, or whether there are some prosodic differences that are not explained by language skills. 


\section{Method}

\subsection{Participants}

The term 'high-functioning autism' (HFA) has been used to describe the condition of people with autism who are verbal and have non-verbal cognitive abilities within the normal range. As previously indicated, the distinction between AS and HFA is controversial. In this research, diagnosis was reached within a multidisciplinary assessment setting, with attention paid to the child's ability to attend, imitate, comprehend and use language, play appropriately with toys, and interact socially as described in a number of settings. Clinical case notes were also reviewed by the fourth author to verify that assignment to HFA and AS was appropriate, based on ICD-10 (World Health Organisation, 1993) and Gillberg and Coleman (2000) respectively, and on history of pre-school language and speech milestones. A range of assessment tools including the Childhood Autism Rating Scale (CARS: Schopler, Reichler, DeVellis, \& Daly, 1980), Gilliam Autism Rating Scale (Gilliam, 1995) and Autism Diagnostic Observation Schedule (ADOS: Lord et al., 2000) were also employed. All children had been identified as having age-appropriate non-verbal cognitive ability. Children were assigned to the HFA group if they had a history of pre-school language delay, and otherwise to the AS group. Children were excluded if any of the following criteria applied: (1) English was not the child's first language and the main language of the home; (2) there was evidence of current hearing loss; (3) receptive language skills were less than 5 years; (4) there was a major physical disability or structural abnormality of the vocal tract; or (5) the family had lived in Scotland for less than 3 years: because prosody varies according to region, this would ensure that all participants were familiar with the variety used in Edinburgh (southern Scottish English). For the HFA group, 31 children met the criteria, and 40 for the AS group.

To control for socioeconomic status, typically-developing children were selected from schools within the same postcode areas as the addresses for the children with ASC. In the HFA study there were 72 typically-developing children, who completed the prosody tasks and a test of receptive vocabulary, the British Picture Vocabulary Scales, 2nd Edition (BPVS-II: Dunn, Dunn, Whetton, \& Burley, 1997). This test was used as a measure of lexical mental age (LMA), following Tager-Flusberg (2000). In the AS study, the control group, who completed the same tasks as the HFA controls, consisted of 47 typicallydeveloping children. From these, it was possible to select similar numbers of children for two control groups each, matched on LMA and on chronological age. As previously stated, we were interested in the development of prosody in lexically-matched groups, but we also wished to compare prosodic skills between children matched for chronological age, because in social situations comparisons are made between children of the same age. There were therefore four groups, not mutually exclusive, of typically-developing participants: two for participants with HFA, one (TD-CM1) matched as closely as possible on age, the other (TD-LM1) matched on lexical mental age; and the other two (TD-CM2 and TD-LM2), similarly matched with the AS group. The exclusion criteria for the typically-developing children were the same as for those with ASC, with the addition that none of the children had a history of speech, language or cognitive delay. Details of participants are shown in Table 1.

\section{Table 1}

Details of sex, age and lexical mental age (LMA) for participants with: high-functioning autism (HFA); Asperger syndrome (AS); typical development matched with HFA on chronological age (TD-CMI); typical development matched with HFA on LMA (TD-LMI); typical development matched with AS on chronological age (TD-CM2); and typical development matched with AS on LMA (TD-LM2).

\begin{tabular}{llllr}
\hline Group & $n$ & Sex (Male/female ratio) & Mean Age (range) & Mean LMA (range) \\
\hline HFA & 31 & $24 / 7$ & $9.8(6.08-13.67)$ & $7.1(4.3-12.83)$ \\
AS & 40 & $34 / 6$ & $9.4(5.83-13.67)$ & $9.6(5.17-17.00)$ \\
TD-CM1 & 31 & $26 / 5$ & $9.8(6.17-13.83)$ & $10.4(7.33-16.17)$ \\
TD-LM1 & 31 & $25 / 6$ & $6.6(4.83-11.25)$ & $7.2(4.58-12.83)$ \\
TD-CM2 & 40 & $35 / 5$ & $9.4(5.83-13.83)$ & $10.2(6.00-16.17)$ \\
TD-LM2 & 40 & $36 / 4$ & $8.9(4.92-17.42)$ & $9.6(5.42-17.00)$ \\
\hline
\end{tabular}




\subsection{Procedures}

A qualified speech and language therapist experienced in testing children with ASC interviewed the children and scored the assessments. The tests were carried out in one-to-one settings in accordance with the relevant manual instructions and in a suitable location such as a quiet room in a pediatric speech and language therapy clinic, a school or the child's home. According to the child's needs or wishes, a parent or carer was also present.

\subsubsection{Lexical mental age and non-verbal ability}

To establish LMA in all participants we used the BPVS-II, which is standardised and has been used as such a measure in other studies of children with ASC (e.g. Baron-Cohen, Leslie, \& Frith, 1985; TagerFlusberg, 2000; Thurber \& Tager-Flusberg, 1993). Non-verbal ability was evaluated using the Raven's Coloured Matrices and Progressive Matrices (RM: Raven, Court, \& Raven, 1986).

\subsubsection{Expressive prosody tasks}

The non-standardised PEPS-C (Peppé \& McCann, 2003) was designed to assess ability in using and understanding the major functions of prosody in speech. In this study, we assessed both receptive and expressive skills, of which expressive skills are relevant to this topic: tasks addressing these are described in Table 2.

Four of the six prosody tasks assess communicative functions: Turn end (the ability to signal whether a conversational turn is ending as a question or a statement), Affect (the expression of liking and disliking by means of intonation and voice quality), Chunking (verbal phrasing) and Contrastive Stress (emphasis, i.e., indicating the most important word in an utterance). The remaining two tasks involve imitation: to discover whether testees have a prosodic repertoire adequate to convey these distinctions, they listen to words (short items) and phrases (long items), and imitate what they hear, copying the way they are said. Imitation task stimuli are a representative sample of those used in the function receptive tasks, in which prosody varies to convey distinct meanings. The function tasks will therefore give a broad picture of the ability of children with ASC to use prosody for communicative function, while the imitation tasks will give an idea of whether any of the children lack any prosodic forms or features necessary for the successful use of prosody. Although we obtained the tester's own opinion as to whether a participant's prosody sounded atypical, none of the PEPS-C tasks directly assesses whether a speaker's prosody in

Table 2

Details of PEPS-C expressive tasks, including task names, an illustration of each task and a description of each task.

\begin{tabular}{|c|c|c|}
\hline Task Name & Example & Description \\
\hline $\begin{array}{l}\text { Turn-end } \\
\text { expression }\end{array}$ & $\begin{array}{l}\text { Picture of carrots on screen, either being } \\
\text { offered or being read from a book }\end{array}$ & $\begin{array}{l}\text { Producing single words with intonation } \\
\text { suggesting either questioning or stating. }\end{array}$ \\
\hline Affect expression & $\begin{array}{l}\text { Picture of carrots on screen. Response: } \\
\text { "Carrots!" (I like them) or } \\
\text { "Carrots..." (I don't like them). } \\
\text { Pictures are followed by a smiling face and a } \\
\text { glum face, to indicate liking and disliking. }\end{array}$ & $\begin{array}{l}\text { Producing affective intonation to } \\
\text { suggest either liking or disliking on } \\
\text { single words. Testee's opinion verified } \\
\text { by subsequent indicating relevant face }\end{array}$ \\
\hline $\begin{array}{l}\text { Chunking } \\
\text { expression }\end{array}$ & $\begin{array}{l}\text { Sock items: picture of pink socks } \\
\text { and black \& green socks, } \\
\text { or of pink \& black socks and green socks. } \\
\text { Food items: pictures of fruit, salad and } \\
\text { milk or of fruit-salad and milk. }\end{array}$ & $\begin{array}{l}\text { Producing prosodic phrase boundaries } \\
\text { in phrases similar to those in the example, } \\
\text { from picture stimuli. }\end{array}$ \\
\hline $\begin{array}{l}\text { Contrastive stress } \\
\text { expression }\end{array}$ & $\begin{array}{l}\text { Cue: "Now the red cow has the ball..." } \\
\text { Response: "No, the red SHEEP has it"; or: } \\
\text { Cue: "The white cow has it": Response: } \\
\text { "No, the BLACK cow has it". }\end{array}$ & $\begin{array}{l}\text { Production of contrastive stress: stressing } \\
\text { the word to be corrected. }\end{array}$ \\
\hline Short-item imitation & $\begin{array}{l}\text { Recording of "Carrots" etc. taken from } \\
\text { Affect and Turn end receptive tasks }\end{array}$ & $\begin{array}{l}\text { Imitation of intonation: testees say what } \\
\text { they hear and copy exactly the way it is said }\end{array}$ \\
\hline Long-item imitation & $\begin{array}{l}\text { Recording of "fish, fingers and fruit" etc. taken } \\
\text { from Chunking and Contrastive } \\
\text { Stress receptive tasks }\end{array}$ & $\begin{array}{l}\text { Imitation of intonation: testees say } \\
\text { what they hear and copy } \\
\text { exactly the way it is said }\end{array}$ \\
\hline
\end{tabular}


general is perceived to be atypical: for this we conducted a perception experiment involving multiple judgments, described in a separate paper (Peppé et al., in preparation).

A vocabulary check at the start of the test ensured that testees were familiar with the items and would use the expected labels for the pictures. Task-items were presented in random order and the tester, sitting out of sight of the screen, made judgments about what the testee was describing by means of a customised keypad connected to the computer. The general instruction for functional expressive tasks was that testees were to say what they saw on the screen. Procedures were first demonstrated by two examples without prosody being modelled. Two practice items ensured that the testee understood the task. Non-practice items were scored as right, wrong or ambiguous for the function tasks: both wrong and ambiguous attracted a score of 0 , right a score of 1 . For the imitation tasks, items were scored as good ( 1 point) fair (half a point) or poor ( 0 ). All responses were judged by at least two raters, and scoring reliability was calculated using $10 \%$ of samples and Cohen's kappa; the means for intra-rater and inter-rater reliability were acceptable at .91 and .82 respectively.

\subsubsection{Expressive language tasks}

The expressive subtests from the Clinical Evaluation of Language Fundamentals (Clinical Evaluation of Language Fundamentals: CELF-3 ${ }^{\mathrm{UK}}$; Semel, Wiig, \& Secord, 2000) were used to assess expressive language skills. Raw scores were used for comparison with results from the non-standardised prosody test.

\subsubsection{Statistical analysis}

Analysis took the form of t-tests for comparing chronological age, non-verbal ability (Raven's Matrices) LMA as determined by the BPVS-II age-equivalent scores, and CELF scores. Raw scores and non-parametric (Mann-Whitney) tests were used for comparing scores from the unstandardised PEPSC, which tended to be non-normally distributed. A $p$ level of $<.05$ was taken as significant.

\section{Results}

\subsection{Chronological age, lexical mental age and non-verbal ability}

The analysis of chronological and lexical mental age differences between the groups can be seen in Table 3.

There was no significant difference in chronological age between the two ASC groups (HFA and AS), but there was a highly significant difference between them in $\operatorname{LMA}(t(67.81)=4.44, p<.001)$, with the AS group (mean 9.6) higher than the HFA group (mean 7.1). There were also, as expected, no significant

\section{Table 3}

Summary of statistical differences in chronological age and lexical mental age (LMA) for participants in groups: high-functioning autism (HFA) and Asperger syndrome (AS); HFA and typical development matched on chronological age with HFA group (TD-CMI); HFA and typical development matched on LMA with HFA group (TD-LMI); AS and typical development matched on chronological age with AS group (TD-CM2); AS and typical development matched on LMA with AS group (TD-LM2); TD-CM1 and TD-LM1; and TD-CM2 and TD-LM2.

\begin{tabular}{lll}
\hline Participant groups & Chronological age & Lexical mental age \\
\hline HFA and AS & ns: $t(69)=.724$, & $t(69)=4.23$, \\
& $p .471$ & $p<.001$ \\
HFA and TD-CM1 & ns: $t(60)=.022$, & $t(60)=5.98$, \\
& $p=.983$ & $p<.001$ \\
HFA and TD-LM1 & $t(60)=6.17$, & ns: $t(60)=.142$, \\
& $p<.001^{*}$ & $p=.887$ \\
AS and TD-CM2 & ns: $t(78)=.045$, & ns: $t(78)=.964$, \\
& $p .964$ & $p .340$ \\
AS and TD-LM2 & ns: $t(78)=.907$, & ns: $t(78)=.009$, \\
& $p .367$ & $p .993$ \\
TD-CM1 and TD-LM1 & $t(60)=6.15$, & $t(60)=5.93$, \\
& $p<.001^{*}$ & $p<.001$ \\
TD-CM2 and TD-LM2 & ns: $t(78)=.944$, & ns: $t(78)=.955$, \\
& $p .348$ & $p .343$ \\
\hline
\end{tabular}


differences of chronological age between the groups selected to match on age, i.e., HFA and TD-CM1, AS and TD-CM2, nor of LMA between the groups selected to match on that measure, i.e., HFA and TD-LM1, AS and TD-LM2. There were highly significant differences between groups as follows:

- LMA lower in the HFA group (mean 7.1) compared to their typically-developing chronological matches, the TD-CM1 (mean 10.4): $t(60)=5.98, p<.001$;

- Chronological age higher in the HFA group (mean 9.4) compared to their typically-developing lexical matches (TD-LM1) (mean 6.6): $t(60)=6.17, p<.001$;

- Chronological age between the two typically-developing groups matching the HFA group: TD-CM1 higher (mean 9.8) than TD-LM1 (mean 6.6): $t(60)=6.15, p<.001$;

- LMA between the same two groups: TD-CM1 higher, mean 10.4, than TD-LM1 (mean 7.2,): $t(60)=5.93, p<.001$.

No such differences were found for the AS group and their controls (TD-CM2 and TD-LM2).

All children with ASC scored within the normal range on the Raven's Matrices test for non-verbal ability, but there was a highly significant difference on this test between the two groups $(t(67)=5.114$, $p<.001)$. There was, however, no significant correlation between expressive prosody scores and nonverbal scores for either group $(p>.05)$.

\subsection{Prosodic ability}

It should be noted that the competence level for the PEPS-C tasks is set at a score of 12 (75\%): this apparently high level targets a particular feature of the test, that if a child uses a prosodically unvarying response, it is possible that this might convey what could be judged as a correct response in $50 \%$ of the task-items. For example, a child with no notion of intonation as either questioning or stating might use the same rising intonation for all responses (as tended to happen significantly more in the HFA group than in a TD group matched for LMA (VMA): Peppé et al., 2007). This would be judged appropriate for all those responses (50\%) that were intended to sound questioning, but a score of $50 \%$ must in such a case be judged to have been obtained by chance. Such chance success could not however occur in more than $50 \%$ of the items, hence the $75 \%$ competence level. Scores $<12$ are therefore below competence level.

Mean raw scores are shown in Figs. 1 and 2. Overall expressive prosodic ability is reduced in both ASC groups, with scores always lower than those of control children.

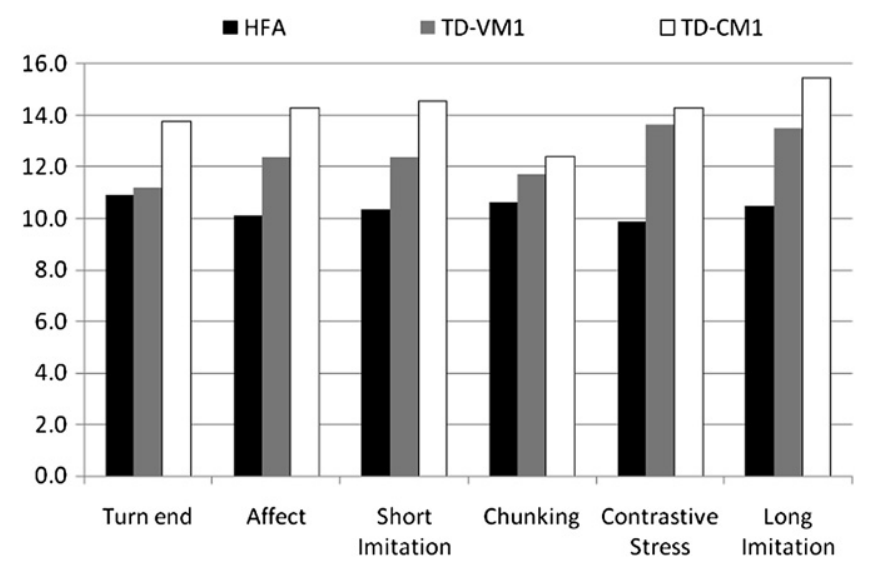

Fig. 1. Average expressive prosody scores from PEPS-C for participants with high-functioning autism (HFA); typical development matched with HFA on lexical mental age (TD-LMI); and typical development matched with HFA on chronological age (TD-CM1). 


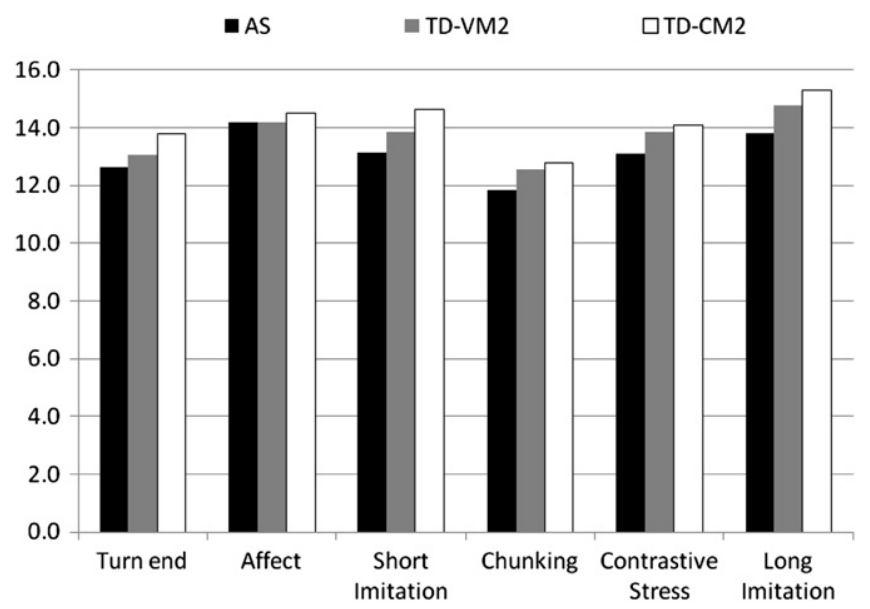

Fig. 2. Average expressive prosody scores from PEPS-C for participants with Asperger syndrome (AS); typical development matched with AS on lexical mental age (TD-LM2); and typical development matched with AS on chronological age (TD-CM2).

\subsubsection{HFA: control comparison}

The HFA group scored significantly lower than LMA-matched children on four expressive prosody tasks: Contrastive Stress $(U=156.5, p<.001)$, Long-item Imitation $(U=202, p<.001)$, Short-item Imitation $(U=310, p<.025)$ and Affect $(U=314.5, p=.029)$.

This group's performance was highly significantly lower than age-matched controls on all tasks, most at the <.001 level (Long-item Imitation: $U=57$; Short-item Imitation: $U=120$; Contrastive Stress: $U=125.5$; Affect: $U=176.5$ and Turn End: $U=223.5 ;$;) only in the Chunking task is the difference at the less significant .01 level $(p=.011, U=290.5)$. Fig. 1 shows a comparison of mean raw scores on prosody tasks from the HFA group and the two TD control groups.

\subsubsection{AS: control comparison}

When comparing AS group prosody scores with those of LMA-matched children, Mann-Whitney tests showed only one significant difference: poorer performance in the AS group on Long-item Imitation $(U=501.5, p=.003)$.

When matching for chronological age, the differences are greater. The AS group performs worse on three tasks: on Long-item Imitation $(U=392, p<.001)$, Short-item Imitation $(U=548.5, p=.013)$, and Chunking $(U=592.5, p=.043)$. Mean raw scores on prosody tasks for the AS groups and their two TD control groups are illustrated in Fig. 2.

\subsubsection{AS: HFA group comparison}

Mann-Whitney tests showed differences between the two ASC groups as significant on five out of six tasks (all except Chunking): Affect $(U=230.5, p<.001)$, Long-item Imitation $(U=232, p<.001)$, Contrastive Stress $(U=267, p<.001)$, Short-item Imitation $(U=297, p<.001)$ and Turn End $(U=402.5$, $p=.018)$, HFA $<$ AS in all cases. The differences on the Chunking task were non-significant $(U=484$, $p=.162$ ), with the AS group producing slightly higher scores.

\subsection{Expressive language ability}

Although the children with AS had no history of pre-school language delay, this did not guarantee normal expressive language skills at school age. Out of the 40 children in the AS group, 14 scored $<85$ on the CELF, thus outside the normal range, of whom 9 scored $<77.5$, i.e., more than 1.5 standard deviations (SDs) below, and of these, 2 participants scored $<70$ (more than 2 SDs below). In the HFA group, two did not complete the CELF tasks, and one of these completed no expressive prosody tasks, 
Table 4

Scores on the Clinical Evaluation of Language Fundamentals (CELF-3 ${ }^{\mathrm{UK}}$ ) for participants with high-functioning autism (HFA) and Asperger syndrome (AS).

\begin{tabular}{llllllll}
\hline Group & $\begin{array}{l}\text { Mean } \\
\text { standard } \\
\text { score (SS) }\end{array}$ & $\begin{array}{l}\text { Range } \\
\text { SS }\end{array}$ & $\begin{array}{l}\text { Mean } \\
\text { age-equivalent (AE) }\end{array}$ & $\begin{array}{l}\text { Range } \\
\text { AE }\end{array}$ & $\begin{array}{l}1 \text { SD } \\
\text { below mean }\end{array}$ & $\begin{array}{l}1.5 \text { SD } \\
\text { below mean }\end{array}$ & $\begin{array}{l}2 \text { SD } \\
\text { below mean }\end{array}$ \\
\hline HFA & 70.72 & $64-95$ & 5.7 & $4-11$ & $89.7 \%$ & $89.7 \%$ & $62.1 \%$ \\
AS & 95.23 & $61-135$ & 8.7 & $5-19$ & $35 \%$ & $25 \%$ & $5 \%$ \\
\hline
\end{tabular}

despite being verbal. Of the remaining 29 participants, 26 scored $<77.5$, of whom 18 scored $<70$, but as previously indicated, specific comparisons between the ASC groups and the TD groups on the CELF tasks are not available because the CELF tasks were not conducted with the typically-developing children in this study. Scores by the two ASC groups on the CELF tasks are shown in Table 4, with standard deviations to indicate what percentages of the groups fall outwith the normal range.

\subsubsection{AS:HFA prosody and language skill comparison}

On the CELF scores, there is a highly significant difference between the two ASC groups: $(t(67)=6$, $p<.001)$, HFA $<$ AS. On the BPVS-II scores, as already mentioned, this is also the case $(t(67.81)=4.44$, $p<.001$ ). Pearson's correlations between individual prosody tasks and CELF scores are highly significant on two tasks for the HFA group: Turn End $(r=.678, p=.003)$ and Contrastive Stress $(r=.541$, $p=.004)$. There are more correlations between prosody and expressive language scores in the AS group than in the HFA group: on Turn End $(r=.475, p=.002)$ and Contrastive Stress $(r=.366, p=.02)$, as in the HFA group, but also (in the AS group) for Short-item Imitation $(.368, p=.02)$, Chunking (.523, $p=.001)$ and Long-item Imitation $(.375, p=.017)$.

\section{Discussion}

Previous research (e.g. Cruttenden, 1985; Wells, Peppé, \& Goulandris, 2004) has established that prosodic development continues during the school years, which accounts for scores at less than competence level on some prosody tasks in the younger(TD-LM1) control group. There was, however, no significant difference between the ages of the two ASC groups, and they could be expected to be at a similar maturational stage; the relative impairment in prosody skills cannot therefore be attributed to their age. While it is of clinical and linguistic interest that there is a discrepancy between the prosody skills of children with ASC and lexically-matched controls, the comparisons between chronological matched groups are more interesting for their social implications, since atypical prosodic ability is likely to relate to what is expected for the children's chronological age. The lack of correlation between scores on the non-verbal ability test and on the prosody tasks in both groups suggests that non-verbal ability, although higher in the AS group, appears not to be a factor influencing expressive prosodic ability.

The comparison of language ability in the various groups of participants is interesting from the point of view of communication impairment in ASC, generally deemed a core characteristic of the condition (Wing \& Gould, 1979). We expected, and found, highly significant differences between the HFA group and their age-matched controls (TD-CM1) on both receptive vocabulary and expressive linguistic skills (in that a large majority of the HFA group, 26 out of 31, scored below the normal range for CELF scores). On the other hand, according to the ICD-10 (World Health Organisation, 1993) and DSM-IV (American Psychiatric Society, 1994), impairment in language is not typical of AS, but for our AS group the picture was mixed. There was a lack of significant difference in receptive vocabulary between the AS group and age-matched controls (TD-CM2), but about a third of the participants with AS scored below the normal range for expressive language skills. This result is at odds with the findings of Szatmari et al. (2009) that there is an absence of structural language impairment in AS: their study is however not strictly comparable with the study discussed here, as they used different diagnostic criteria. Nevertheless, in our study the two experimental groups differed significantly on both receptive vocabulary and expressive language skills (with higher scores by the AS group). As Szatmari et al. (2009) suggest, both ASC groups may follow a similar trajectory in linguistic development, but our 
study also suggests real between-group differences in stages of maturation of language skills. The implications for the study of children with ASC are that where aspects of language and communication are concerned, participants should be distinguished as to whether they have AS or an ASC with more severe language impairment, whereas many studies concerning communication in ASC show no differences on language measures between participants with ASC and TD controls (e.g. Diehl, Watson, Bennetto, McDonough, \& Gunlogson, 2009; Grossman, Bemis, Plesa Skwerer, \& Tager-Flusberg, 2010; Paul et al, 2005).

Mean prosody scores of the AS group are higher than for the HFA group, and there is a wider gap between the HFA group and their TD peers than for the AS group. However, the highly significant difference between the two groups on the CELF scores and the good correlation between the CELF and many prosody scores (particularly in the AS group) suggest that poorer language ability may well explain at least some of the poor prosodic performance of the children with ASC. Assessment of prosodic ability thus confirms and amplifies the diagnosis of poor language skills. Some of the prosodic impairment is not explained by poor language, however: for example, HFA scores were significantly lower than those of the LMA-matched TD group on the prosodic expression of Affect task, and these scores do not correlate with the same children's CELF scores. This could indicate an atypical trajectory for prosodic development, at least in the HFA group.

\subsection{Communicative effectiveness in HFA and AS groups}

The prosody scores suggest that imitation of prosody is poor in both ASC groups. This is consistent with the findings of other studies (e.g. Williams, Whiten, Suddendorff, \& Perrett, 2001) that children with ASC have difficulty in executing imitation tasks. It has however been noted (anecdotally) that children with ASC can adopt the accent and speech mannerisms of characters in videos with great accuracy. Our results may therefore owe something to the fact that we presented imitation as a formal task, i.e., asked participants to imitate utterances apparently purposelessly and in a non-spontaneous way, although this appears to cause no problem for the TD groups. The ability to imitate prosody is, however, not crucial to the functionality of prosody. Some of the children showed a mildly restricted repertoire, e.g. lacking a fall-rise tone or having very narrow pitch-span; some showed a tendency to use the same intonation contour repeatedly.

Chunking, or prosodic phrasing, is below competence level in both ASC groups, and relatively impaired compared with typically-developing children (especially age-matched controls). Deficit in this skill suggests that listeners may be unclear as to how speech is phrased within a conversational turn, e.g. whether a word is a separate item or describing another; on the whole, context and semantics will ensure that the message is not misleading or unintelligible, but poor chunking prosody is likely to hinder processing; results suggest that this is not likely to be a major problem in ASC. Closer analysis of responses suggests that the most frequent atypical prosodic exponent was a failure to lengthen final syllables to indicate the end of a chunk; final-syllable lengthening has been established as a feature of prosodic delimitation (de Pijper \& Sanderman, 1994; Sanderman \& Collier, 1997).

The Contrastive Stress task assesses the aspect of prosody that has been noted as atypical in earlier studies (Baltaxe \& Guthrie, 1987;). Contrastive stress involves greater acoustic prominence, and signals that a particular word is the most important in an utterance: typically, it falls on a 'new' word, one that has not been recently uttered either by speaker or interlocutor. An utterance will sound odd if the new word is deaccented and stress falls instead on a 'given' one, but intelligibility is likely to be affected only if this switch in expected stress-placement is accompanied by so little prominence on the new item that it is inaudible; the problem here is therefore more likely to be a matter of sounding atypical than of being misleading. The contrastive stress task attracts the lowest expressive mean score in the HFA group, whereas it appears to be one of the earliest acquired prosodic skills in typically-developing children (Wells, Peppé \& Goulandris, 2004). In the AS group, however, the mean score is above the competence level and not significantly different from the TD group scores. Baltaxe and Guthrie (1987) found a tendency in children with ASC to shift the stress towards the beginning of utterances, and this was borne out in our HFA study (Peppé et al., 2007). In the AS study, we found less of this tendency, with ambiguous responses comprising the bulk of errors (62.2\%), then utterances where the stress was placed on the second item rather than the first (21.9\%) and stress shifted on to the first item in $15.8 \%$. 
Children with ASC are typically said to display little emotion in their voices; this feature was suggested originally by Kanner (1943) and often anecdotally since, but see Hubbard and Trauner (2007) for acoustic analysis showing complex differences by comparison with controls. The Affect scores in the HFA group suggest inaccurate or ambiguous renditions of emotion. Clearly it is communicatively disadvantageous to have one's feelings misinterpreted, even if this is more a paralinguistic than a strictly linguistic or functional use of prosody. As with the Contrastive Stress scores, however, there is a big significant difference between the two ASC groups on the Affect scores, suggesting that the AS group is likely to be less misleading or ambiguous in this respect.

The Turn End task scores show the HFA group below competence and the AS group having achieved it. An 'error' in the intonation of a question or a statement will, however, often be resolved in practice by context and semantics (as with chunking prosody), and the consequences of such errors are more that listeners may have to adjust their interpretations, rather as necessitated by the recent trend to 'uptalk', or high-rising terminals (Cruttenden, 1995), than that there is a misunderstanding.

\section{Conclusion}

Our findings suggest that the prosody of children with ASCs may be confusing for listeners: broadly speaking, children with Asperger's syndrome have this problem to a lesser degree than children with HFA. Children with HFA scored poorly on all the prosody tasks, suggesting that their speaking intentions could well be misinterpreted or hard to understand. By contrast, children with Asperger's syndrome, compared with age-matched typically-developing participants, have fewer problems: they show difficulty with verbal phrasing and punctuation, as indicated by their scores on the Chunking task, and also with the imitation tasks: if impaired imitation is a core deficit in ASC, then a difficulty in imitating prosody may be an obstacle to learning prosody in the first place. Differences between the ASC groups and the TD groups were more pronounced when comparing them on chronological rather than lexical age, suggesting that prosody skills may lag in maturity in both HFA and Asperger's syndrome and contribute to social difficulties. Since prosody is an aspect of language, it was likely that language impairment would account for differences of prosodic ability. However, the fact that children with ASC, particularly the HFA group, perform worse than their lexically-matched TD peer groups on some aspects of prosody indicates that factors other than language skills are at work, and the lack of correlation between some prosody scores and the expressive language task supports this. Our data does not however allow direct comparison between prosodic and expressive linguistic skills in the TD groups, because these children did not complete the CELF tasks. We can say that prosody skills appear to be associated with 'functioning levels' in autism but have not enough information to conclude whether this is due to the linguistic aspect of prosody or to other aspects of prosody (e.g. Theory of Mind). If the difference were due only to language impairment then we would expect other children with language disorders, e.g. specific language impairment (SLI), to show prosodic impairments; but atypical expressive prosody is not usually observed as a feature of specific language impairment. In this respect, however, the overlap between ASC and specific language impairment should be borne in mind (e.g. Bishop \& Norbury, 2002). A further study investigating children with specific language impairment using the same test battery would indicate whether such atypical prosody was characteristic of language impairment or peculiar to ASC. A recent study using some of the PEPS-C subtests concluded that prosody was not a core impairment in these children (Marshall, Harcourt-Brown, Ramus, \& van der Lely, 2009), with children with specific language impairment and/or dyslexia having no difficulty imitating prosody. However, a further study of children with specific language impairment using the full PEPS-C battery could be revealing.

Our finding that a large proportion of the children, especially in the HFA group, showed prosodic impairment has implications both for clinical intervention and for diagnosis. With regard to intervention, our findings strengthen the case for intervention targeting the prosodic ability of people with ASC. With regard to diagnosis, since there appeared to be some prosodic impairment independent of language ability, it is possible that atypical prosody might be a contributing diagnostic factor in ASC. It is interesting to note that a measure of atypical prosody is included in the ADOS assessment, but because the variability in examiners' judgments is too great it is not actually incorporated into the diagnostic algorithm (LeCouteur, personal communication). It might, however, be possible to amend 
the measure according to the methodology used here and achieve better agreement. This presents a possibility for future research, with the aim of producing a measure that would help to differentiate between levels of ability in high-functioning individuals with ASC.

\section{Acknowledgments}

The authors are grateful to the UK Economic and Social Research Council and to the Scottish Health Executive's Chief Scientist Office for funding (grants RES-000-23-0555 and CZB 4/34 respectively) that wholly supported the research reported here.

\section{References}

American Psychiatric Society. (1994). Diagnostic and statistical manual for mental disorders (4th ed.). Washington, D.C: American Psychiatric Publishing, Inc.

Baltaxe, C., \& Guthrie, D. (1987). The use of primary sentence stress by normal, aphasic and autistic children. Journal of Autism and Developmental Disorders, 17, 255-271.

Baron-Cohen, S., Leslie, A. M., \& Frith, U. (1985). Does the autistic child have a "theory of mind"? Cognition, 21, 37-46.

Ben Shalom, D., Mostofsky, S. H., Hazlett, R. L., Goldberg, M. C., Landa, R. J., Faran, Y., et al. (2006). Normal physiological emotions but differences in expression of conscious feelings in children with high-functioning autism. Journal of Autism and Development Disorders, 36(3), 395-400.

Bishop, D. V. M., \& Norbury, C. F. (2002). Exploring the borderlands of autistic disorder and specific language impairment. Journal of Child Psychology and Psychiatry, 43(7), 917-929.

Capps, L., Yirmiya, N., \& Sigman, M. (1992). Understanding of simple and complex emotions in non-retarded children with autism. Journal of Child Psychology and Psychiatry, 33(7), 1169-1182.

Cederlund, M., Hagberg, B., Billstedt, E., Gillberg, I. C., \& Gillberg, C. (2008). Asperger syndrome and autism: a comparative longitudinal follow-up study more than 5 years after diagnosis. Journal of Autism and Developmental Disorders, 38, 72-85.

Cruttenden, A. (1985). Intonation comprehension in ten-year-olds. Journal of Child Language, 12, 643-661.

Cruttenden, A. (1995). Rises in English. In J. Windsor Lewis (Ed.), Studies in general and English phonetics (pp. 155-173). London: Routledge.

Diehl, J. J., Watson, D., Bennetto, L., McDonough, J., \& Gunlogson, C. (2009). An acoustic analysis of prosody in high-functioning autism. Applied Psycholinguistics, 30, 385-404.

Dunn, L., Dunn, L., Whetton, C., \& Burley, J. (1997). The British picture vocabulary scale. Windsor: NFER-Nelson.

Ehlers, S., \& Gillberg, C. (1993). The epidemiology of Asperger's syndrome: a total population study. Journal of Child Psychology and Psychiatry, 34, 1327-1350.

Fitzgerald, M., \& Corvin, A. (2001). Diagnosis and differential diagnosis of Asperger syndrome. Advances in Psychiatric Treatment, 7, 310-318.

Gillberg, C., \& Coleman, M. (2000). The biology of the autistic syndromes (3rd ed).. London: MacKeith Press.

Gilliam, J. E. (1995). Gilliam Autism Rating Scale (GARS). Austin, Tx: PRO-ED.

Grossman, R. B., Bemis, R. H., Plesa Skwerer, D., \& Tager-Flusberg, H. (2010). Lexical and affective prosody in children with highfunctioning autism. Journal of Speech, Language, and Hearing Research, 53, 778-793.

Harrison, M. J., O'Hare, A. E., Campbell, H., Adamson, A., \& McNeillage, J. (2006). Prevalence of autistic spectrum disorders in Lothian, Scotland: an estimate using the "capture-recapture" technique. Archive of Disorders in Childhood, 91, 16-19.

Howlin, P. (2003). Outcome in high-functioning adults with autism with and without early language delays: implications for the differentiation between autism and Asperger syndrome. Journal of Autism and Developmental Disorders, 33, 3-13.

Hubbard, K., \& Trauner, D. A. (2007). Intonation and emotion in autistic spectrum disorders. Journal of Psycholinguistic Research, $36,159-173$.

Lord, C., Risi, S., Lambrecht, L., Cook, E. H., Leventhal, B. L., DiLavore, P. C., et al. (2000). The autism diagnostic observation schedule-generic: a standard measure of social and communication deficits associated with the spectrum of autism. Journal of Autism and Developmental Disorders, 30, 205-223.

Kanner, L. (1943). Autistic disturbances of affective contact. Nervous Child, 2, 217-250.

Klin, A., \& Volkmar, F. R. (1995). Asperger's syndrome guidelines for assessment and diagnosis. Yale child study center, New Haven, Connecticut: Learning Disabilities Association of America.

Macintosh, K. E., \& Dissayanake, C. (2004). Annotation: the similarities and differences between autistic disorder and Asperger's syndrome. A review of the empirical evidence. Journal of Child Psychology and Psychiatry, 45, 421-434.

Marshall, C., Harcourt-Brown, S., Ramus, F., \& van der Lely, H. (2009). The link between prosody and language skills in children with specific language impairment (SLI) and/or dyslexia. International Journal of Language and Communication Disorders, 44, 466-488.

Matson, J. L. (2007). Current status of differential diagnosis for children with autism spectrum disorders. Research Developmental Disabilities, 28, 109-118.

McCann, J., \& Peppé, S. (2003). Prosody in autism spectrum disorders: a critical review. International Journal of Language and Communication Disorders, 38, 325-350.

McCann, J., Peppé, S., Gibbon, F., O'Hare, A., \& Rutherford, M. (2007). Prosody and its relationship to language in school-aged children with high-functioning autism. International Journal of Language and Communication Disorders, 42(6), 682-702.

Paul, L., Augustyn, A., Klin, A., \& Volkmar, F. (2005). Perception and production of prosody by speakers with autism spectrum disorders. Journal of Autism and Developmental Disorders, 35, 205-220.

Peppé, S. J. E. (2009). Why is prosody in speech-language therapy so difficult? International Journal of Speech-Language Pathology, 11(4), 258-271. 
Peppé, S., Cleland, J., Gibbon, F., O’Hare, A., Martinez Castilla, P., \& Lickley, R. (in preparation). Perception and functionality of atypical prosody in autism spectrum disorders.

Peppé, S., McCann, J., Gibbon, F., O’Hare, A., \& Rutherford, M. (2007). Receptive and expressive prosodic ability in children with high-functioning autism. Journal of Speech, Language and Hearing Research, 50, 1015-1028.

Peppé, S., \& McCann, J. (2003). Assessing intonation and prosody in children with atypical language development: the PEPS-C test and the revised version. Clinical Linguistics and Phonetics, 17, 345-354.

Raven, J., Court, J., \& Raven, J. (1986). Raven's progressive matrices and Raven's coloured matrices. London: H.K.Lewis.

Roach, P. (2000). English phonetics and phonology. Cambridge: CUP.

de Pijper, J. R., \& Sanderman, A. A. (1994). On the perceptual strength of prosodic boundaries and its relation to suprasegmental cues. Journal of Acoustical Society of America, 96(4), 2037-2047.

Sanderman, A. A., \& Collier, R. (1997). Prosodic phrasing and comprehension. Language and Speech, 40, 391-409.

Schopler, E., Reichler, R. J., DeVellis, R. F., \& Daly, K. (1980). Toward objective classification of childhood autism: Childhood Autism Rating Scale (CARS). Journal of Autism and Developmental Disorders, 10, 91-103.

Semel, E., Wiig, E. H., \& Secord, W. (2000). Clinical evaluation of language fundamentals - Third Edition (UK) (CELF-3 $\left.{ }^{U K}\right)$. London: Psychological Corporation.

Shriberg, L., Paul, R., McSweeny, J., Klin, A., Cohen, D., \& Volkmar, F. (2001). Speech and prosody characteristics of adolescents and adults with high-functioning autism and Asperger's Syndrome. Journal of Speech, Language, and Hearing Research, 44, 1097-1115.

Szatmari, P., Bryson, S., Duku, E., Vaccarella, L., Zwaigenbaum, L., Bennett, T., et al. (2009). Similar developmental trajectories in autism and Asperger syndrome: from early childhood to adolescence. Journal of Child Psychology and Psychiatry, 50, 1459-1467.

Tager-Flusberg, H. (2000). Language and understanding minds: connections in autism. In S. Baron-Cohen, H. Tager-Flusberg, \& D. J. Cohen (Eds.), Understanding other minds: Perspectives from autism and developmental cognitive neuroscience (2nd ed). (pp. 124-149,). Oxford: Oxford University Press.

Thurber, C., \& Tager-Flusberg, H. (1993). Pauses in the narratives produced by autistic, mentally-retarded, and normal-children as an index of cognitive demand. Journal of Autism and Developmental Disorders, 23, 309-322.

Wells, B., Peppé, S., \& Goulandris, A. (2004). Intonation development from five to thirteen. Journal of Child Language, 31, 749-778.

Williams, J. H. G., Whiten, A., Suddendorff, T., \& Perrett, D. (2001). Imitation, mirror neurons and autism. Neuroscience and Biobehavioural Review, 25, 287-295.

Wing, L. (1981). Asperger's syndrome: a clinical account. Psychological Medicine, 11, 115-129.

Wing, L. (1991). Asperger's syndrome and Kanner's autism. In U. Frith (Ed.), Autism and Asperger syndrome (pp. 93-121). Cambridge: Cambridge University Press.

Wing, L., \& Gould, J. (1979). Severe impairments of social interaction and associated abnormalities in children: epidemiology and classification. Journal of Autism and Developmental Disorders, 9, 11-29.

World Health Organisation. (1993). The ICD-10 classification of mental and behavioural disorders. Geneva: World Health Organisation. 